\title{
TMEM16A contributes to angiotensin II-induced cerebral vasoconstriction via the RhoA/ROCK signaling pathway
}

\author{
RONG-SHAN LI ${ }^{1}$, YONG WANG ${ }^{1}$, HUI-SHEN CHEN ${ }^{1}$, FANG-YONG JIANG $^{1}$, \\ QIANG TU ${ }^{2}$, WEN-JUN LI ${ }^{2}$ and RUI-XING YIN ${ }^{3}$ \\ Departments of ${ }^{1}$ Cardiology and ${ }^{2}$ Examination, Liuzhou People's Hospital, Liuzhou, Guangxi 545006; \\ ${ }^{3}$ Department of Cardiology, The First Affiliated Hospital of Guangxi Medical University, Nanning, Guangxi 530021, P.R. China
}

Received March 18, 2015; Accepted January 20, 2016

DOI: $10.3892 / \mathrm{mmr} .2016 .4979$

\begin{abstract}
Calcium activated chloride channels (CaCCs) are critical in vascular smooth muscle function as they regulate proliferation/apoptosis of smooth muscle cells (SMCs) and vascular tone. Transmembrane protein 16A (TMEM16A) was demonstrated to encode CaCCs in basilar artery SMCs (BASMCs) and participate in basilar artery remodeling during hypertension. In addition, TMEM16A has recently been illustrated to contribute to pressure-induced myogenic response in cerebral vasculature. However, whether TMEM16A is involved in cerebral vasoconstriction that is stimulated by other vasoconstrictors remains unclear. The aim of the present study was to establish whether TMEM16A is involved in the progression of angiotensin II (Ang II)-induced basilar artery constriction and elucidate its potential role during hypertension. The study demonstrated that the specific inhibitor of TMEM16A, T16A-inhA01 attenuated Ang II-induced constriction in rat basilar arteries, and that this effect was weakened in parallel with the decline of TMEM16A expression in basilar arteries of 2-kidney, 2-clip hypertensive rats. Furthermore, it was found that $100 \mathrm{nM}$ Ang II evoked a chloride current in cultured BASMCs with a basal 100-nM intracellular $\mathrm{Ca}^{2+}\left(\left[\mathrm{Ca}^{2+}\right]_{\mathrm{i}}\right)$ level. In addition, the current could be abolished by TMEM16A small interfering RNA pretreatment and Ang II receptor type 1 (AT1) receptor blocker, losartan, while Ang II failed to cause a further increase to $\mathrm{Ca}^{2+}$-dependent $\mathrm{Cl}^{-}$currents activated by $500 \mathrm{nM}\left[\mathrm{Ca}^{2+}\right]_{\mathrm{i}}$. In addition, in cultured BASMCs, Ang II
\end{abstract}

Correspondence to: Dr Wen-Jun Li, Department of Examination, Liuzhou People's Hospital, 8 Wenchang Road, Liuzhou, Guangxi 545006, P.R. China

E-mail: liwenjun2010@126.com

Dr Rui-Xing Yin, Department of Cardiology, The First Affiliated Hospital of Guangxi Medical University, 6 Shuangyong Road, Nanning, Guangxi 530021, P.R. China

Email: ruistaryes@sina.com

Key words: transmembrane protein 16A, angiotensin II, cerebral vasoconstriction, RhoA/Rho-associated protein kinase signaling pathway induced phosphorylation of myosin phosphatase-targeting subunit 1 , and myosin light chains were significantly enhanced by TMEM16A overexpression, which were reversed by Rho-associated protein kinase (ROCK) inhibitor, Y-27632, while TMEM16A silencing demonstrated an opposing result. Furthermore, Ang II-induced RhoA activation was enhanced by TMEM16A overexpression. In conclusion, the present study revealed that Ang II elicited a TMEM16A-mediated current and TMEM16A participated in Ang II-induced basilar constriction via the RhoA/ROCK signaling pathway.

\section{Introduction}

Hypertension is currently one of the most serious public health challenges worldwide. It is a major risk factor for cardiovascular diseases, myocardial infarction, stroke and chronic renal failure (1). Vascular tone, which represents the contractile activity of vascular smooth muscle cells (VSMCs) in the small arteries and arterioles, is the major determinant of vascular resistance to blood flow through the circulation, rendering it a particularly important component of hypertension (2). Enhanced vascular contractility contributes to the long-term control of systemic blood pressure (3), and impaired cerebral vasoconstriction during hypertension affects brain regional blood flow, which makes it a risk factor for stroke (4). Ion channels have been demonstrated to be critical in vascular tone and the development of hypertension, and numerous investigations into the role of ion channels in arterial smooth muscle contractility have been conducted. In these studies, cation channels, including calcium channel, voltage-dependent, $\mathrm{L}$ type, $\alpha 1 \mathrm{C}$ subunit, various $\mathrm{K}^{+}$channels (5) and nonselective transient receptor potential (TRP) channels (6) have been found to regulate vascular contraction (1). Anion channels, such as chloride channels are also involved. Chloride channels within the plasma membrane of VSMCs cause $\mathrm{Cl}^{-}$efflux and membrane depolarization (7), and $\mathrm{Ca}^{2+}$-activated chloride currents (CaCCs) may be involved in increasing vascular contractility. CaCC-dependent depolarization activates voltage-gated $\mathrm{Ca}^{2+}$ channels (8) and further increase intracellular $\mathrm{Ca}^{2+}\left(\left[\mathrm{Ca}^{2+}\right]_{\mathrm{i}}\right)$, resulting in signal amplification, leading to VSMC contraction and contractile response of blood vessels. Transmembrane protein 16A (TMEM16A) was recently identified to be responsible for the CaCCs in basilar artery SMCs (BASMCs) 
and it is involved in the regulation of BASMCs proliferation during hypertension (9). Previous research regarding cerebral vasculature has revealed that pressure-induced membrane stretch may activate TMEM16A channels and thus contribute to the myogenic tone of basilar arteries (10). In addition to blood pressure, constriction of resistance arteries is also regulated by vasoconstrictors, such as angiotensin II (Ang II), thromboxane A2 and 5-hydroxytryptamine; however, whether TMEM16A channels are also involved in vasoconstrictor-induced cerebral vasoconstriction remains unclear.

The renin-angiotensin system (RAS) is key in cardiovascular and renal physiology, and its overactivation is implicated in the induction and progression of hypertension (11). Circulating Ang II, the major contributing factor of the RAS, was significantly upregulated during hypertension (12), establishing it as an important and high-risk pathologic factor. Ang II acts directly on vascular smooth muscle as a vasoconstrictor in an either calcium-dependent or -independent manner; in the latter case, Ang II activates the RhoA/Rho-associated protein kinase (ROCK) signaling pathway and increases VSMC Ca ${ }^{2+}$ sensitization via Rho guanine nucleotide exchange factors (13), inducing phosphorylation of myosin phosphatase-targeting subunit 1 (MYPT1) and myosin light chains (MLCs), which finally causes SMC contraction. In a previous study, it was found that basilar artery constriction in response to Ang II was mediated by ROCK, while the vasoconstriction in response to $\mathrm{KCl}$ was not significantly influenced by this signaling pathway (14).

In the present study, the role of TMEM16A in Ang II-induced basilar artery vasoconstriction was investigated using its specific inhibitor, T16A-inhA01 $(9,15)$. The basilar arteries were obtained from hypertensive rats at various time-points following 2-kidney, 2-clip (2k2c) surgery, and the influence of ROCK inhibitor, Y-27632 was also detected. Notably, the direct effect of Ang II on TMEM16A-mediated CaCC channels was determined in cultured BASMCs, and it was further revealed that the TMEM16A protein expression level affected Ang II-induced phosphorylation of MYPT1 and MLC via the RhoA/ROCK signaling pathway.

\section{Materials and methods}

Animal models and blood pressure measurement. The present study was approved by the ethics committee of Liuzhou People's Hospital (Liuzhou, China). All animal experimental procedures were performed according to the policies of the Second Medical University Animal Care and Use Committee and conformed to the Guide for the Care and Use of Laboratory Animals (16). Unless otherwise stated, all materials were purchased from Sigma-Aldrich (St. Louis, MO, USA). Hypertensive rat models $(2 \mathrm{k} 2 \mathrm{c})$ were established, as described previously (17). Briefly, 120 healthy male Sprague-Dawley rats (weight, 80-120 g; Laboratory Animal Centre, Guangxi Medical University, Nanning, China) were anaesthetized by sodium pentobarbital (40 mg/kg, i.p.), and following midline laparotomy, ring-shaped silver clips (internal diameter, $0.3 \mathrm{~mm}$ ) were placed around the two renal arteries. All animals were maintained in a pathogen-free room with controlled temperature at $\sim 25^{\circ} \mathrm{C}$, under a 12-h light/dark cycle. Blood pressure was measured in conscious rats by tail-cuff plethysmography (Powerlab 4/30; ADInstruments Pty Ltd., Bella Vista, NSW, Australia).

Basilar artery lumen diameter measurement. Following induction of deep anesthesia (pentobarbital; $200 \mathrm{mg} / \mathrm{kg}$ i.p.), the brain was removed from each of the rats and placed in Krebs buffer containing: $137 \mathrm{mM} \mathrm{NaCl}, 5.4 \mathrm{mM} \mathrm{KCl}, 2.0 \mathrm{mM} \mathrm{CaCl}_{2}$, $1.1 \mathrm{mM} \mathrm{MgCl}_{2}, 0.4 \mathrm{mM} \mathrm{NaH}_{2} \mathrm{PO}_{4}, 5.6 \mathrm{mM}$ glucose, $11.9 \mathrm{mM}$ $\mathrm{NaHCO}_{3}, 105 \mathrm{U} / 1$ penicillin and $100 \mathrm{mg} / \mathrm{l}$ streptomycin, at $37^{\circ} \mathrm{C}$. Basilar arteries were rapidly isolated and the connective tissue was carefully removed. As described previously (18), arteries were mounted onto glass micropipettes filled with Krebs buffer in an organ chamber, and allowed to equilibrate and reach a stable diameter for $\geq 30 \mathrm{~min}$ at a distending pressure of $60 \mathrm{mmHg}$. The stimuli and/or inhibitors were subsequently added. Ang II $\left(10^{-11}-10^{-7} \mathrm{M}\right)$ was added for $5 \mathrm{~min}$ for measurement and T16A-inhA01 $(10 \mu \mathrm{M})$ and Y-27632 $(10 \mu \mathrm{M})$ were added 5 min prior to Ang II stimulation. Vessel images were captured using an AxioImager Z1 microscope (Zeiss GmbH, Jena, Germany) and an S-100 video camera (Nikon Corporation, Tokyo, Japan), a VDA-10 electronic dimension analyzer (Living Systems Instrumentation, St. Albans, VT, USA) was then used to measure the lumen diameter.

Cell culture. Rat BASMCs were cultured from the rat basilar arteries, as previously described (19). Briefly, healthy male Sprague-Dawley rats (weight, 80-100 g) were anaesthetized with pentobarbital sodium (200 mg/kg i.p.). Basilar arteries were harvested immediately and immersed in iced Kreb's solution. The vessels were isolated carefully and sliced into 0.2-mm rings in Dulbecco's modified Eagle's medium/Ham's F-12 (DMEM/F12) medium and the vessel segments were placed on the surface of the culture flask and incubated in DMEM/F12 medium supplemented with $20 \%$ fetal bovine serum (FBS; Thermo Fisher Scientific, Inc., Waltham, MA, USA) at $37^{\circ} \mathrm{C}$, in an atmosphere of $5 \% \mathrm{CO}_{2}$ for 5-7 days. Cells from passage 3-6 were used in subsequent experiments.

Recording of CaCC currents in cultured BASMCs. The $\mathrm{Ca}^{2+}$-activated $\mathrm{Cl}^{-}$current was recorded from cultured BASMCs using an Axopatch ${ }^{\text {TM }}$ 200B Amplifier (Molecular Devices, LLC, Sunnyvale, CA, USA) according to a previously described, whole-cell patch clamp technique (20). The current was elicited using voltage steps from 60 to $100 \mathrm{mV}$ in $20-\mathrm{mV}$ increments for $250 \mathrm{msec}$ from a holding potential of $-40 \mathrm{mV}$ and stored on a computer following digitalization at $5 \mathrm{kHz}$ using a Digidata 1322A (Axon Instrument). The bath solution contained $1.5 \mathrm{mM} \mathrm{CaCl}_{2}, 1 \mathrm{mM} \mathrm{MgCl}_{2}, 10 \mathrm{mM} \mathrm{NaCl}$, $140 \mathrm{mM}$ NMDG-Cl, $10 \mathrm{mM}$ HEPES and $10 \mathrm{mM}$ glucose, which was adjusted to $\mathrm{pH} 7.4$ using $\mathrm{HCl}$. The $\mathrm{Ca}^{2+}$-buffered pipette solution contained $140 \mathrm{mM} \mathrm{CsCl}, 1 \mathrm{mM} \mathrm{MgCl}_{2}$, 5 mM EGTA, $10 \mathrm{mM}$ HEPES, $4 \mathrm{mM} \mathrm{Na}{ }_{2}$-ATP, and 1.925 and $3.801 \mathrm{mM} \mathrm{CaCl}_{2}$ to adjust the free $\mathrm{Ca}^{2+}$ concentration to 100 and $500 \mathrm{nM}$, respectively (calculated using the CaBuf program; www.jgp.org/cgi/content/full/jgp.201411339/DC1), which was adjusted to $\mathrm{pH} 7.2$ using $\mathrm{CsOH}$. The pipettes (Sutter Instrument Co, Novato, CA, USA) were pulled from borosilicate glass capillaries and had resistances of 3-5 M $\Omega$ after fire polishing. All experiments were performed at room temperature $\left(22-25^{\circ} \mathrm{C}\right)$. 
TMEM16A small interfering (si)RNA and adenovirus transfection. siRNA duplex (40 nM) against rat TMEM16A gene (sense, 5'-GGAGUUAUCAUCUAUAGAATT-3' and antisense, 5'-UUCUAUAGAUGAUAACUCCAA-3'; Qiagen $\mathrm{GmbH}$, Hilden, Germany) was transiently transfected with Hiperfect Transfection Reagent (Qiagen $\mathrm{GmbH}$ ), as previously described (19). A scrambled RNA (Qiagen $\mathrm{GmbH}$ ) served as the negative control. Briefly, the siRNA strand and Hiperfect Transfection Reagent were diluted in serum- and antibiotic-free DMEM/F12 and maintained at room temperature for $10 \mathrm{~min}$ to form the transfection complexes. The complexes were added to BASMCs and mixed gently to ensure uniform distribution. Following incubation for $3 \mathrm{~h}$ at $37^{\circ} \mathrm{C}$, transfection complexes were replaced with normal DMEM/F12 medium containing 10\% FBS for $48 \mathrm{~h}$. TMEM16A adenovirus (adv-TMEM16A) was constructed by Shengbo Biological Engineering Co., Ltd. (Shanghai, China). The adv-TMEM16A (multiplicity of infection, 200) was added into cultured BASMCs with serum- and antibiotic-free DMEM/F12 for $6 \mathrm{~h}$, then cells were washed twice with phosphate-buffered saline and cultured in DMEM/F12 medium containing 10\% FBS for another 48 h. adv-lacz (Jikai Biological Engineering Co., Ltd., Shanghai, China) served as a negative control. Western blot analysis was used to examine the effect of TMEM16A siRNA (si-TMEM16A) and adv-TMEM16A.

Western blot analysis. Samples were gathered and protein was sequentially extracted according to the instructions of the Cell Lysis Buffer for Western and IP protein extraction kit (Beyotime Institute of Biotechnology, Shanghai, China). Protein concentrations in the samples were quantified by bicinchoninic acid protein assay using the BCA Protein assay kit (Beyotime Institute of Biotechnology). Protein $(50 \mu \mathrm{g})$ was loaded into each lane and separated by $10 \%$ SDS-PAGE (Beyotime Institute of Biotechnology) by electrophoresis, and transferred at $200 \mathrm{~mA}$ for $1.5 \mathrm{~h}$ onto a polyvinylidene fluoride membrane (EMD Millipore, Billerica, MA, USA). After blocking in blocking buffer [PBS ( $\mathrm{pH} 7.4$ ) 5\% skimmed milk powder and $0.05 \%$ Tween-20] for $1 \mathrm{~h}$ at room temperature, the membrane was incubated with primary and secondary antibodies. Rabbit polyclonal TMEM16A antibody was obtained from Novus Biologicals, LLC (Littleton, CO, USA; cat. no. NBP1-60076; dilution, 1:500). Rabbit polyclonal MLC (cat. no. 3672; dilution, 1:1,000), mouse monoclonal phosphorylated (p)-MLC (cat. no. 3675; dilution, 1:1,000), rabbit polyclonal MYPT1 (cat. no. 2634; dilution, 1:1,000) and rabbit polyclonal p-MYPT1 (cat. no. 5163; dilution, 1:1,000), were from Cell Signaling Technology, Inc. (Danvers, MA, USA). Mouse monoclonal GAPDH as purchased from Santa Cruz Biotechnology, Inc. (Dallas, TX, USA; cat. no. sc-365062; dilution, 1:2,000). Horseradish peroxidase-conjugated goat anti-rabbit (cat. no. sc-2004; dilution, 1:1,000) and goat anti-mouse (cat. no. sc-2005; dilution, 1:1,000) immunoglobulin $G$ antibodies were purchased from Santa Cruz Biotechnology, Inc. Detection was performed with the Immobilon Western Chemiluminescent HRP Substrate system (EMD Millipore).

RhoA activity assay. The change in RhoA activity results from the shift between the active GTP-bound state and the
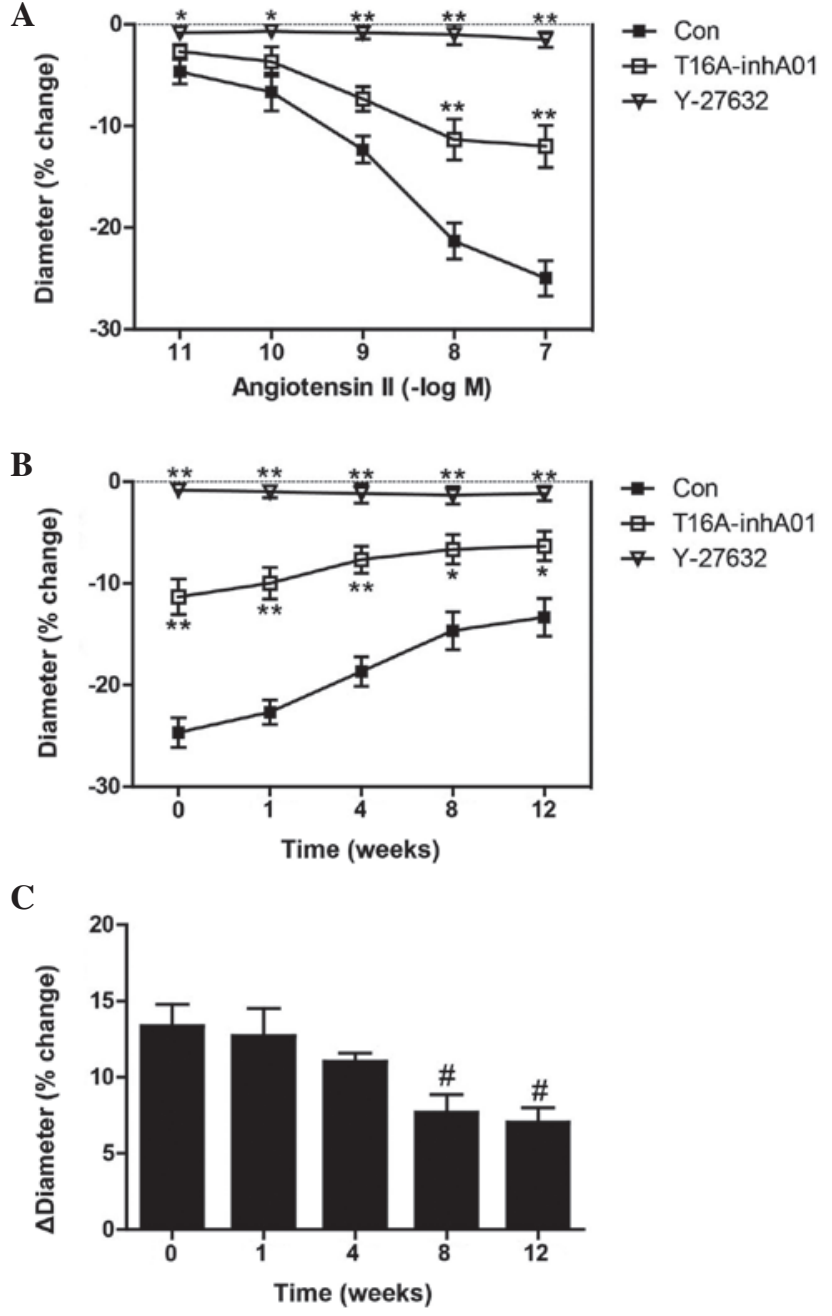

Figure 1. Inhibition of transmembrane protein 16A decreases rat basilar artery constriction in response to varying concentrations of Ang II. (A) Constriction of the basilar artery in response to Ang II in the absence and presence of T16A-inhA01 $(10 \mu \mathrm{M})$ or Y-27632 $(10 \mu \mathrm{M})$. (B) Constriction of the rat basilar arteries at week 0 , and 1, 4, 8 and 12 weeks following 2-kidney, 2-clip surgery, in response to $100 \mathrm{nM}$ Ang II, and in the absence and presence of T16A-inhA01 or Y-27632. (C) The bar graph indicates that T16A-inhA01 induced a decrease in the $\triangle$ Diameter in the presence of $100 \mathrm{nM}$ Ang II. ${ }^{*} \mathrm{P}<0.05,{ }^{* *} \mathrm{P}<0.01$ vs. Con; ${ }^{\#} \mathrm{P}<0.05$ vs. week $0(\mathrm{n}=6) . \Delta$ Diameter, basilar artery diameter; Ang II, angiotensin II; Con, control.

inactive guanosine diphosphate (GDP)-bound state. A RhoA Activation assay kit (Abcam, Cambridge, MA, USA) was used to detect the GTP-RhoA/RhoA ratio in the present study. The experiment was conducted according to the manufacturer's instructions. Briefly, BASMCs were washed twice with ice-cold PBS and lysed in the supplied lysis buffer $(1 \mathrm{mM}$ phenylmethanesulfonyl fluoride, $10 \mu \mathrm{g} / \mathrm{ml}$ leupeptin and $10 \mu \mathrm{g} / \mathrm{ml}$ aprotinin were added just prior to usage). Cell lysates were quantified as described above and total RhoA detection was performed using western blotting. For GTP-RhoA detection, the lysates were incubated with anti-active RhoA mouse monoclonal antibody and protein $\mathrm{A} / \mathrm{G}$ agarose beads at $4^{\circ} \mathrm{C}$ in an end-over-end mixer (Shanghai Xiyuan Technology Development Co., Ltd., Shanghai, China) for $1 \mathrm{~h}$. The beads were subsequently collected by centrifugation at $5,000 \mathrm{x} \mathrm{g}$ for $1 \mathrm{~min}$ at $4^{\circ} \mathrm{C}$ and washed three times with assay/lysis buffer, and were boiled for $5 \mathrm{~min}$ and centrifuged at 5,000 $\mathrm{x} \mathrm{g}$ for 


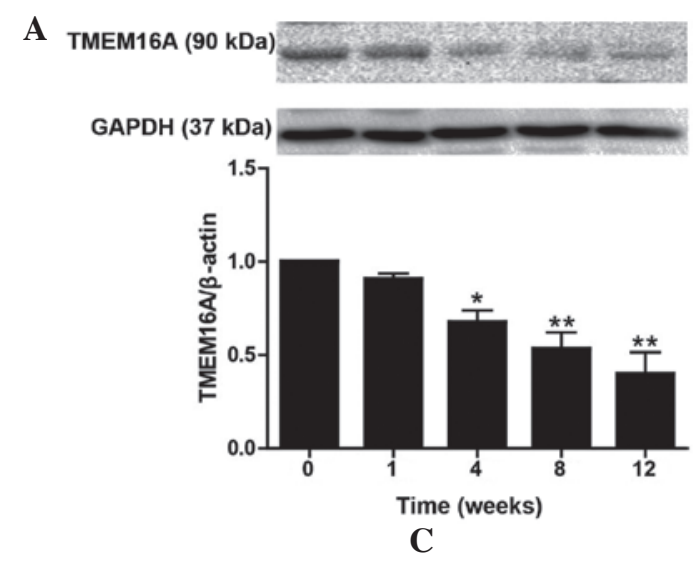

$\mathbf{B}$
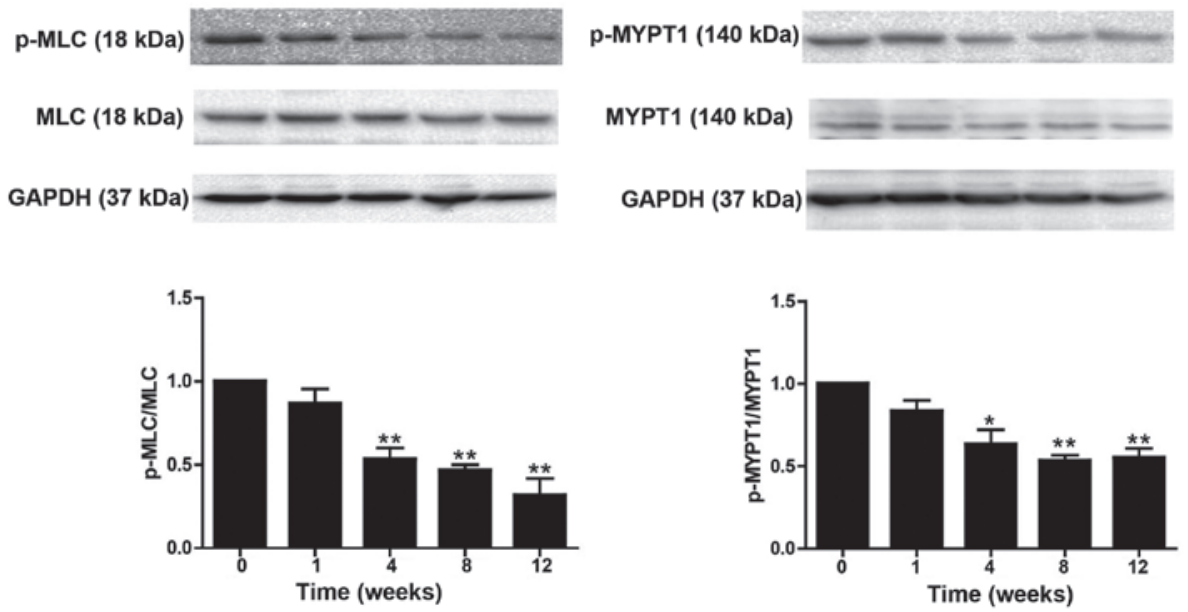

Figure 2. Decreased expression of TMEM16A, p-MLC/MLC and p-MYPT1/MYPT1 in rat basilar arteries during the development of hypertension. (A) Western blot analysis of TMEM16A in basilar arteries at various time-points after 2-kidney, 2-clip surgery. Western blot analysis of phosphorylation of (B) MLC and (C) MYPT1 in basilar arteries. GAPDH served as a loading control. ${ }^{*} \mathrm{P}<0.05,{ }^{* *} \mathrm{P}<0.01$ vs. week 0 ( $\left.\mathrm{n}=6\right)$. TMEM16A, transmembrane protein 16A; MLC, myosin light chain; MYPT1, myosin phosphatase-targeting subunit 1; p, phosphorylated.

$10 \mathrm{sec}$ at $\sim 25^{\circ} \mathrm{C}$. The pull-down supernatant was then subjected to western blot analysis. An anti-RhoA antibody served as the primary antibody and the secondary antibody was anti-rabbit (included in the RhoA activation assay kit).

Statistical analysis. Statistical analyses were performed using GraphPad Prism 5.0 (GraphPad Software, Inc., La Jolla, CA, USA). All data were expressed as mean \pm standard error of the mean, Student's t-test was used to test for differences between two groups, and one-way analysis of variance was used to test for differences among the treatment groups followed by the Bonferroni multiple comparison post hoc test. $\mathrm{P}<0.05$ was considered to indicate a statistically significant difference.

\section{Results}

TMEM16A activity inhibition decreases Ang II-induced constriction in rat basilar arteries. Constriction of rat basilar artery in response to Ang II has previously been observed (14). The effect of a specific TMEM16A inhibitor, T16A-inhA01 on varying concentrations of Ang II induced basilar artery constriction (diameter change, \%) was assessed in the present study. T16A-inhA01 $(10 \mu \mathrm{M})$ partly reversed the Ang II-induced reduction in diameter of basilar arteries at $10(\mathrm{P}<0.01)$ and $100 \mathrm{nM}(\mathrm{P}<0.01)$ and
Rho kinase inhibitor, Y-27632 abolished the effect of Ang II (Fig. 1A) at 0.01, $0.1(\mathrm{P}<0.01), 1,10$ and $100 \mathrm{nM}(\mathrm{P}<0.05)$. Ang II (100 nM) was used in subsequent experiments. Similar results were observed in $2 \mathrm{k} 2 \mathrm{c}$ hypertensive rats, and Ang II-induced constriction was gradually decreased in $2 \mathrm{k} 2 \mathrm{c}$ hypertension rats (Fig. 1B). Furthermore, it was found that the T16A-inhA01-induced reduction in basilar artery constriction ( $\triangle$ Diameter; $\%$ change) in the presence of $100 \mathrm{nM}$ Ang II gradually decreased during the development of hypertension at 8 weeks $(\mathrm{P}<0.05)$ and 12 weeks $(\mathrm{P}<0.05$; Fig. 1C), indicating less involvement of TMEM16A during progression of hypertension, which was consistent with the decreased level of TMEM16A protein expression in basilar arteries at $4(\mathrm{P}<0.05), 8(\mathrm{P}<0.01)$ and 12 weeks $(\mathrm{P}<0.01$; Fig. 2A). Phosphorylation of MLC and MYPT1 in basilar arteries from the hypertensive rats was also detected; western blot analysis demonstrated that p-MLC/MLC was significantly downregulated in a time-dependent manner at 4, 8 and 12 weeks (all $\mathrm{P}<0.01$ ) and $\mathrm{p}-\mathrm{MYPT} 1 / \mathrm{MYPT} 1$ was also significantly downregulated at $4(\mathrm{P}<0.05), 8(\mathrm{P}<0.01)$ and 12 weeks $(\mathrm{P}<0.01)$ with the progression of hypertension (Fig. 2B and C), presenting further evidence of the reduced contractility of basilar arteries. These data strongly indicate that TMEM16A is involved in cerebral vasoconstriction during hypertension. 
A

a

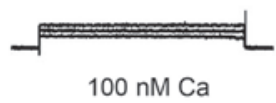

c

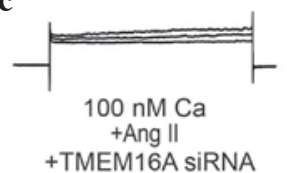

d

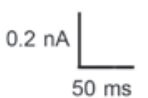

e

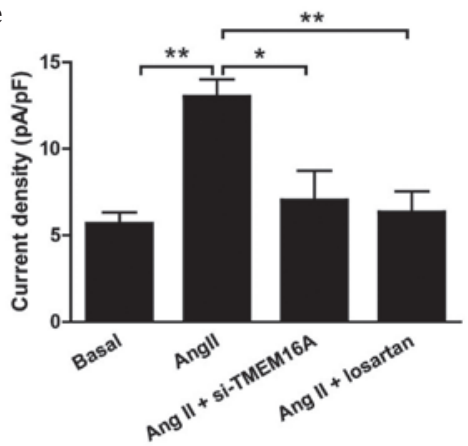

B

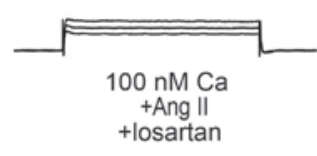

a

b
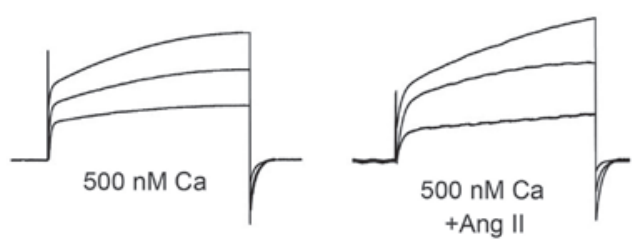

c

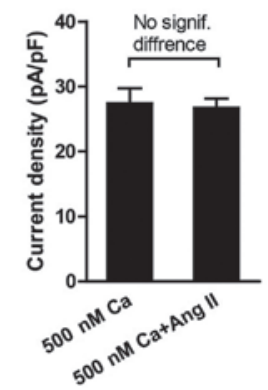

Figure 3. Ang II evoked a TMEM16A-mediated current using $100 \mathrm{nM}\left[\mathrm{Ca}^{2+}\right]_{\mathrm{i}}$ in BASMCs. (A) Representative traces of $\mathrm{I}_{\mathrm{Cl.Ca}}$ recorded in BASMCs. Cells were immersed in a bath solution and the current was recorded using a whole-cell patch clamp with (a) a basal intracellular calcium concentration $\left(100 \mathrm{nM}\left[\mathrm{Ca}^{2+}\right]_{\mathrm{i}}\right)$ and (b) immediately after $100 \mathrm{nM}$ Ang II was perfused into the bath solution. Results from BASMCs pretreated with (c) TMEM16A siRNA and 100 nM [Ca $\left.{ }^{2+}\right] \mathrm{i}, 100 \mathrm{nM}$ Ang II-induced current for $48 \mathrm{~h}$ or (d) $10 \mu \mathrm{M}$ losartan for $15 \mathrm{~min}$. (e) Bar graph of current density at $100 \mathrm{mV}$ in the different groups. (B) $\mathrm{I}_{\mathrm{CICa}}$ was recorded in BASMCs with (a) $500 \mathrm{nM}\left[\mathrm{Ca}^{2+}\right]_{\mathrm{i}}$ and (b) the current wasn't enhanced by $100 \mathrm{nM}$ Ang II. (c) Bar graph of current density at $100 \mathrm{mV}$ in the two groups. ${ }^{*} \mathrm{P}<0.05,{ }^{* *} \mathrm{P}<0.01$ ( $\left.\mathrm{n}=8-11\right)$. Ang II, angiotensin II; TMEM16A, transmembrane protein $16 \mathrm{~A} ;\left[\mathrm{Ca}^{2+}\right]_{\mathrm{i}}$, intracellular $\mathrm{Ca}^{2+} ; \mathrm{BASMC}$, basilar artery smooth muscle cell; $\mathrm{I}_{\mathrm{CICa}}, \mathrm{Ca}^{2+}$-dependent $\mathrm{Cl}^{-}$channel.

A

TMEM16A

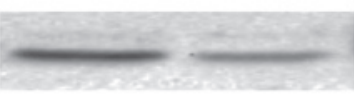

GAPDH
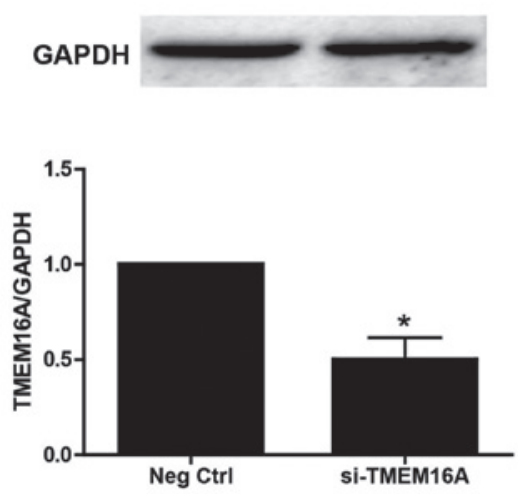

B
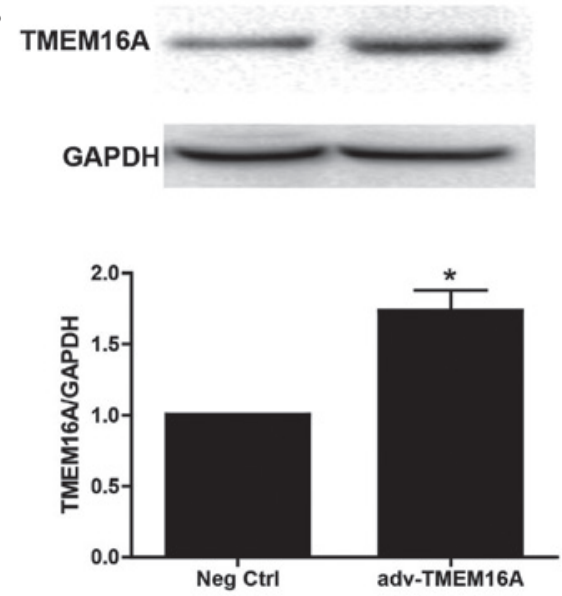

Figure 4. Effect of si-TMEM16A and adenovirus on TMEM16A expression in BASMCs. BASMCs were treated with (A) si-TMEM16A or (B) adv-TMEM16A for 3 and $6 \mathrm{~h}$, respectively, and then cultured with 10\% fetal bovine serum and Dulbecco's modified Eagle's medium/Ham's F-12 medium for another $48 \mathrm{~h}$. TMEM16A protein expression was detected by western blot analysis and GAPDH served as a loading control. " $\mathrm{P}<0.05$ vs. Neg Ctrl. $\mathrm{n}=4$. TMEM16A, transmembrane protein 16A; BASMC, basilar artery smooth muscle cell; Neg Ctrl, negative control; si-TMEM16A, TMEM16A siRNA; adv-TMEM16A, TMEM16A adenovirus.

Ang II elicits a TMEM16A-mediated CaCC current in BASMCs. In VSMCs, Ang II stimulates $\mathrm{Ca}^{2+}$-dependent $\mathrm{Cl}^{-}$channel $\left(\mathrm{I}_{\mathrm{Cl} . \mathrm{Ca}}\right)$ activity via increasing $\left[\mathrm{Ca}^{2+}\right]_{\mathrm{i}}(21,22)$. $\mathrm{Ca}^{2+}$-induced $\mathrm{I}_{\mathrm{Cl} . \mathrm{Ca}}$
(CaCCs) in BASMCs was reported previously and TMEM16A was demonstrated to be a critical component of $\mathrm{CaCCs}$ in basilar arteries (19). To investigate whether Ang II directly 
A
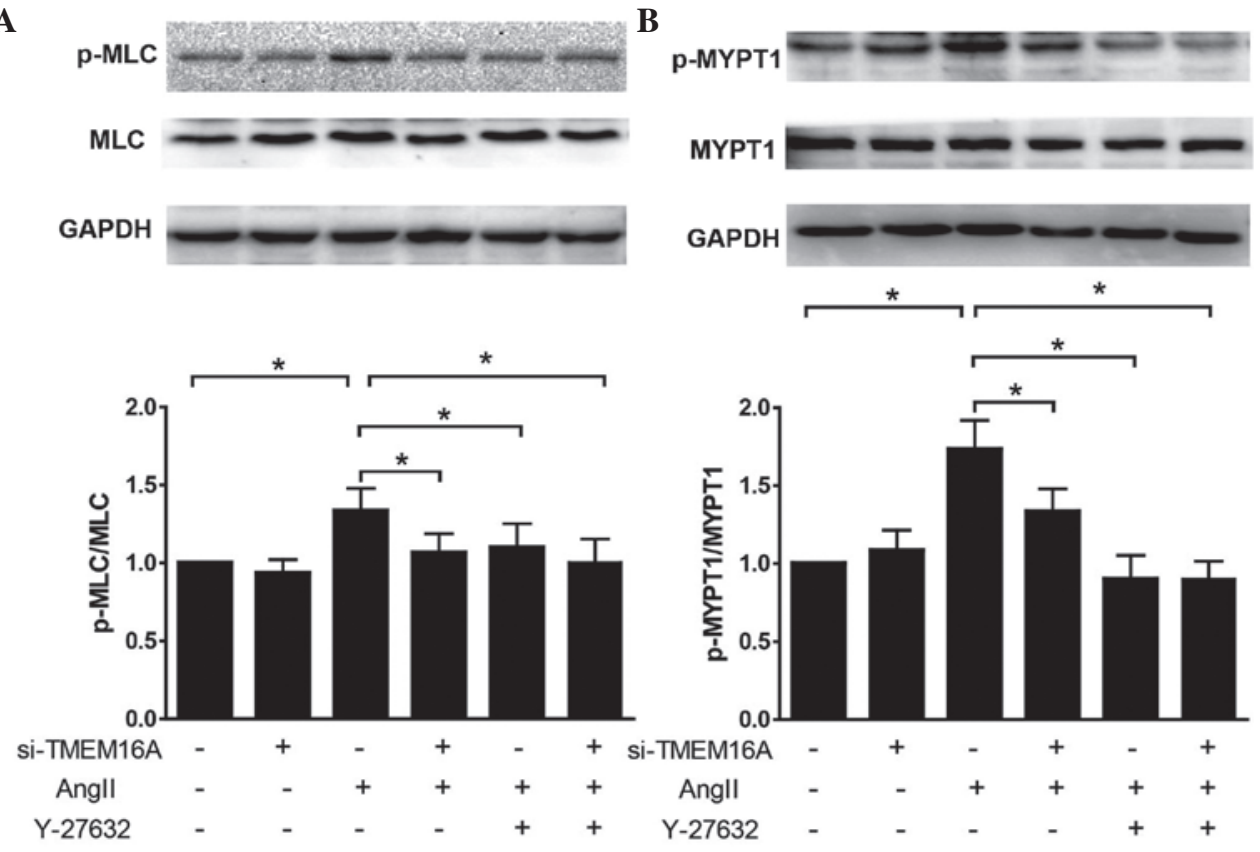

C

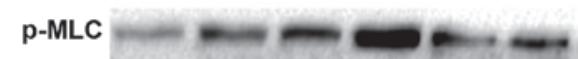

MLC
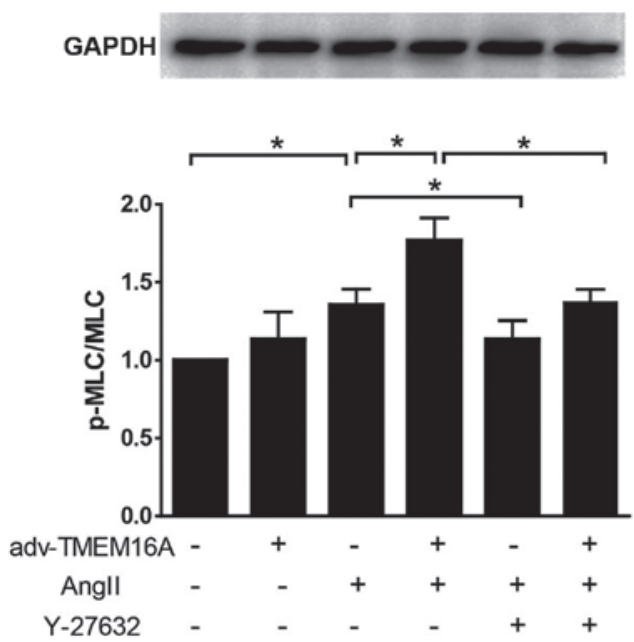

D
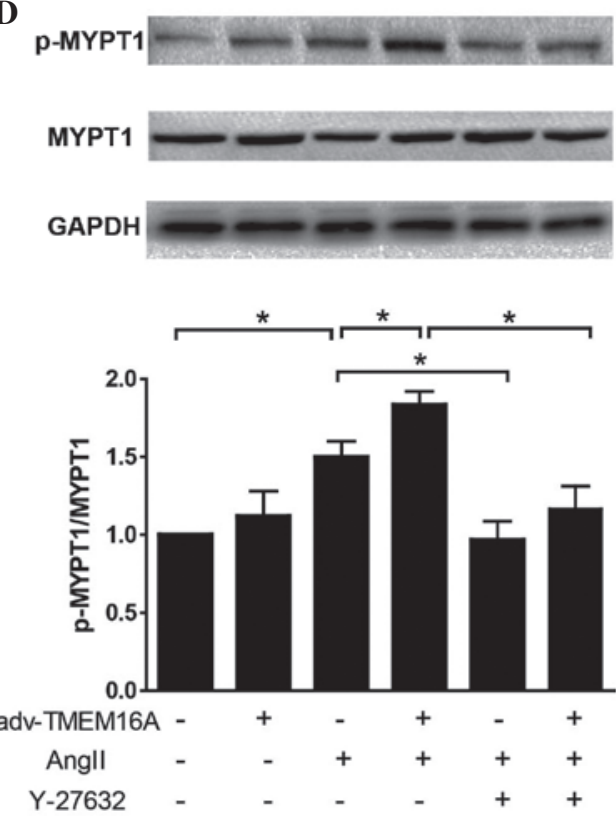

Figure 5. Regulation of Ang II-induced phosphorylation of MLC and MYPT1 by TMEM16A expression. BASMCs were treated with (A and B) si-TMEM16A or (C and D) adv-TMEM16A for $3 \mathrm{~h}$ or $6 \mathrm{~h}$ and cultured for another $48 \mathrm{~h}$. Y-27632 (10 $\mu \mathrm{M})$ was added $10 \mathrm{~min}$ before the 5-min treatment of $100 \mathrm{nM}$ Ang II. Cell lysates were collected and phosphorylation of (A and C) MLC and (B and D) MYPT1 were detected by western blot analysis. GAPDH served as a loading control. * $\mathrm{P}<0.05 ; \mathrm{n}=8$. Ang II, angiotensin II; MLC, myosin light chain; MYPT1, myosin phosphatase-targeting subunit 1; TMEM16A, transmembrane protein 16A; si, small interfering; si-TMEM16A, TMEM16A siRNA; BASMC, basilar artery smooth muscle cell; p, phosphorylated; adv-TMEM16A, TMEM16A adenovirus.

elicits TMEM16A-mediated CaCC channels, the effect of $100 \mathrm{nM}$ Ang II on $100 \mathrm{nM}\left[\mathrm{Ca}^{2+}\right]_{\mathrm{i}}$-induced $\mathrm{I}_{\mathrm{Cl} . \mathrm{Ca}}$ (basal $\mathrm{I}_{\mathrm{Cl} . \mathrm{Ca}}$ ) and $500 \mathrm{nM}\left[\mathrm{Ca}^{2+}\right]_{\mathrm{i}}$-induced $\mathrm{I}_{\mathrm{Cl} \text {.Ca }}$ in BASMCs was analyzed. As shown in Fig. 3, Ang II enhanced basal $\mathrm{I}_{\mathrm{Cl} . \mathrm{Ca}}$ to $\sim 0.2 \mathrm{nA}$ $(\mathrm{P}<0.01$; Fig. 3Aa and $\mathrm{Ab})$ and this increase was abolished when cells were pretreated with TMEM16A siRNA $(\mathrm{P}<0.05)$ and $10 \mu \mathrm{M}$ angiotensin type 1 (AT1) receptor blocker, losartan $(\mathrm{P}<0.01$; Fig. 3Ac and Ad). In addition, it was demonstrated that Ang II did not enhance the $500 \mathrm{nM}\left[\mathrm{Ca}^{2+}\right]_{\mathrm{i}}$-induced $\mathrm{I}_{\mathrm{Cl} . \mathrm{Ca}}$ further (Fig. 3Ba and Bb), indicating that this Ang II-elicited current was contained in TMEM16A-mediated CaCCs.
Effect of TMEM16A expression on phosphorylation of MLC and MYPT1 in BASMCs in response to Ang II and the influence of $Y$-27632. si-TMEM16A and adv-TMEM16A were evaluated in cultured BASMCs (Fig. 4) TMEM16A expression levels were significantly decreased by si-TMEM16A $(\mathrm{P}<0.01)$ and increased by adv-TMEM16A. They were then used to test the effect of TMEM16A expression on cell contractility in response to Ang II. Western blot analysis demonstrated that downregulation of TMEM16A by si-TMEM16A decreased Ang II-induced phosphorylation of MLC and MYPT1 (Fig. 5A and B), while upregulation of TMEM16A by adv-TMEM16A 
A

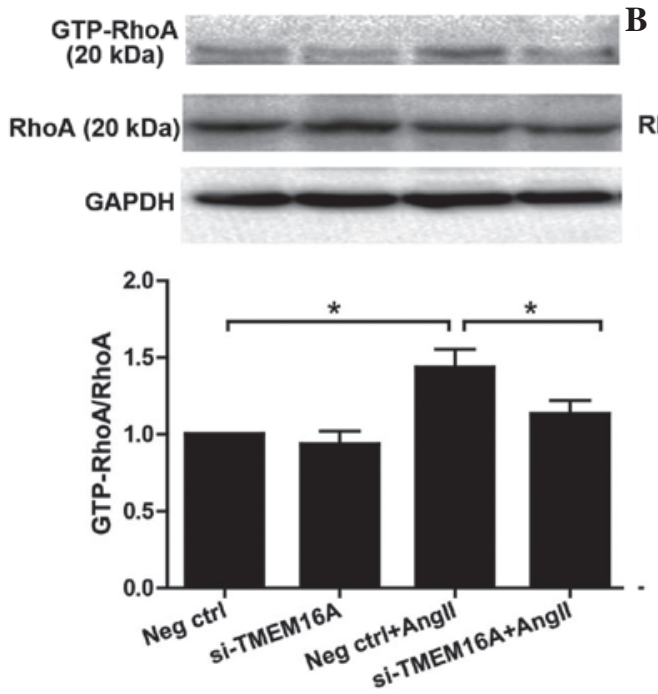

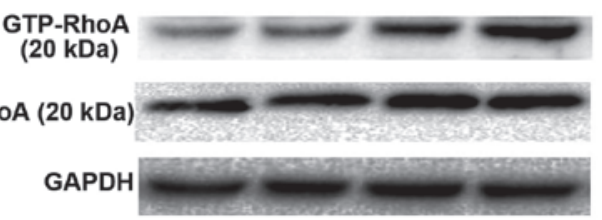

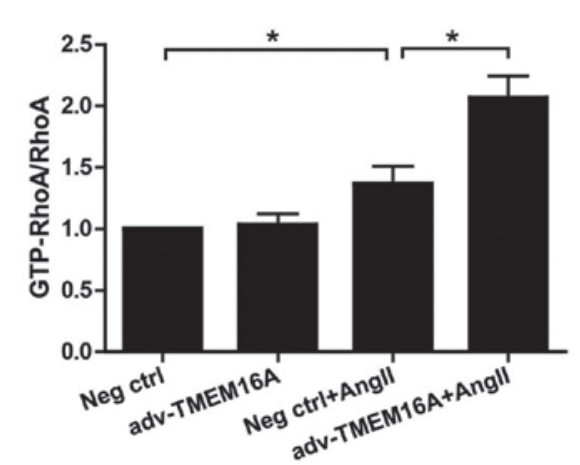

Figure 6. Expression of GTP-RhoA/RhoA in cultured BASMCs in response to $100 \mathrm{nM}$ Ang II following TMEM16A downregulation or overexpression. BASMCs were treated with (A) si-TMEM16A or (B) adv-TMEM16A for $3 \mathrm{~h}$ or $6 \mathrm{~h}$ and then cultured with $10 \%$ fetal bovine serum and Dulbecco's modified Eagle's medium/Ham's F-12 medium for another $48 \mathrm{~h}$. AngII (100 nM) was added for 5 min to induce cell contraction. Cell lysates were collected and GTP-RhoA and RhoA were detected by western blot analysis. GAPDH served as a loading control. * $\mathrm{P}<0.05$; n=8. GTP, guanosine-5'-triphosphate; BASMC, basilar artery smooth muscle cell; TMEM16A, transmembrane protein 16A; si, small interfering; si-TMEM16A, TMEM16A siRNA; adv-TMEM16A, TMEM16A adenovirus; Neg Ctrl, negative control.

increased Ang II-induced phosphorylation of MLC $(\mathrm{P}<0.01)$ and MYPT1 ( $<<0.01$; Fig. 5C and D). As shown in Fig. 1 and consistent with a previous study (14), Ang II-induced vasoconstriction is mediated to a great extent by ROCK. To investigate whether TMEM16A affects Ang II cell contractility via ROCK, a ROCK inhibitor, Y-27632 was applied to BASMCs treated with si-TMEM16A or adv-TMEM16A, and the data demonstrated that Y-27632 reversed the increase of contractility caused by overexpression of TMEM16A ( $\mathrm{P}<0.01$; Fig. 5C and D), indicating that TMEM16A regulates Ang II-induced contraction of SMCs by affecting the RhoA/ROCK signaling pathway.

TMEM16A enhances Ang II-induced phosphorylation of MYPT1 and MLC in BASMCs by increasing RhoA activity. As shown in Fig. 1A and B, and Fig. 5C and D, TMEM16A regulated smooth muscle contraction in response to Ang II by affecting the RhoA/ROCK signaling pathway, therefore, the direct effect of TMEM16A on Ang II-induced RhoA activation was evaluated in BASMCs. BASMCs were pretreated with si-TMEM16A or adv-TMEM16A and then GTP-RhoA; the activated RhoA was detected following treatment of $100 \mathrm{nM}$ Ang II for $5 \mathrm{~min}$. Western blotting showed that downregulation of TMEM16A decreased the Ang II-induced GTP-RhoA increase $(\mathrm{P}<0.01$; Fig. 6A), while upregulation of TMEM16A further increased Ang II-induced augmentation of GTP-RhoA $(\mathrm{P}<0.01$; Fig. 6B).

\section{Discussion}

The results of the present study demonstrate that TMEM16A participates in basilar artery constriction via the RhoA/ROCK signaling pathway. The following were evidenced by the current study: i) Cerebral vascular contractility decreased in the $2 \mathrm{k} 2 \mathrm{c}$ hypertensive rat model, which was indicated by the decreased basilar artery constriction in response to Ang II, and by decreased phosphorylation of MLC and MYPT1; ii) the TMEM16A inhibitor, T16A-inhA01 partly inhibited Ang II-induced basilar artery constriction, and the inhibition ratio was decreasing as the hypertension progressed, in parallel with a decline in the level of TMEM16A protein expression; iii) Ang II elicited CaCC in BASMCs, which was blocked by si-TMEM16A and the AT1 receptor inhibitor, losartan. Notably, Ang II did not further enhance the $500 \mathrm{nM}$ $\left[\mathrm{Ca}^{2+}\right]_{\mathrm{i}}$-activated $\mathrm{I}_{\mathrm{Cl} \text {.Ca }}$, which has been demonstrated as a TMEM16A-mediated CaCC in BASMCs, indicating that the Ang II-elicited current and the $500 \mathrm{nM}\left[\mathrm{Ca}^{2+}\right]_{\mathrm{i}}$-induced current were mediated by the same channel, TMEM16A. The data from the present study provide the first direct evidence of the association between Ang II and activation of the TMEM16A channel in cerebral SMCs; and iv) TMEM16A overexpression increased Ang II-induced phosphorylation of MYPT1 and MLC by regulating RhoA activation in BASMCs. TMEM16A downregulation decreased Ang II-induced phosphorylation of MYPT1 and MLC by regulating RhoA activation in BASMCs.

In the circulatory system, vascular resistance is critical for regulating partial constriction. Small resistance arteries (such as mesenteric, renal and basilar arteries) constrict when subjected to $\mathrm{KCl}$ (depolarization), which increases intraluminal pressure and levels of vasoconstrictors, such as endothelin 1 and Ang II (23). The mechanisms of various stimuli (including endothelin-1, 5-hydroxytryptamine and thromboxane A2) have been investigated in past decades, and the present study focuses on cerebral vasoconstriction induced by Ang II (24-26). Ang II is the primary effector pleiotropic hormone of the RAS cascade, which mediates physiological control of electrolyte balance and blood pressure (27). Ang II exerts its effect via activation of two receptor subtypes, AT1 and AT2 $(28,29)$; the AT1 receptor is noteworthy, as it is critical in regulating vessel constriction and blood pressure (30). 
Earlier studies of cerebral arteries have demonstrated the vasoconstrictor effects of Ang II on vascular tone $(31,32)$, and the effects are generally considered to result from the activation of AT1 receptors, which in turn stimulate phospholipase C (PLC) and phospholipase A2 (PLA2). PLC and PLA2 then generate inositol trisphosphate $/ \mathrm{Ca}^{2+}$ and diacylglycerol/protein kinase $\mathrm{C}$, which activate multiple downstream signaling cascades that result in SMC contraction (33). Ang II has been reported to affect numerous ion channels, such as the large conductance $\mathrm{Ca}^{2+}$-activated $\mathrm{K}^{+}$channel, a key determinant of vascular tone (34), TRP cation channels (35) and voltage-dependent $\mathrm{Ca}^{2+}$ channels (36). In the present study, the influence of Ang II on CaCCs was elucidated in BASMCs. Previous studies hypothesized TMEM16A to be an important component of CaCCs $(20,37,38)$ and its function was then widely investigated. It has been reported that TMEM16A is critical in $\mathrm{Cl}^{-}$secretion of epithelial cells of the airways $(20,39)$, SMC proliferation and the nervous system by controlling the excitability of various neurons. A strong association between $\mathrm{CaCC}$ activity and the concentration of free $\mathrm{Ca}^{2+}$ has been demonstrated in previous studies $(40,41)$. Ang II is involved in the regulation of intracellular $\mathrm{Ca}^{2+}$, therefore, the present study hypothesized whether Ang II influenced $\mathrm{I}_{\mathrm{Cl} \text {.Ca }}$ in BASMCs. The data indicates that Ang II directly evoked TMEM16A-mediated CaCCs and the inhibition of which suppressed constriction of the basilar arteries, indicating that TMEM16A may be involved in Ang II-induced cerebral vasoconstriction. In addition, the effect of TMEM16A inhibitor, T16A-inhA01 [a compound that inhibited CaCC currents in TMEM16A-transfected Fisher rat thyroid cells with a half maximal inhibitory concentration of $\sim 1 \mu \mathrm{M}$ (42)], on the constriction of basilar arteries in response to Ang II was analyzed in the present study. The data showed that inhibition of TMEM16A reduced Ang II-induced basilar artery constriction, and the impact of the inhibitor was abrogated in the hypertensive rats. Ang II acts as a vasoconstrictor for acute stimulation and, in the long term, causes vascular remodeling. The increase of plasma Ang II levels in hypertensive rats is attributed to vascular remodeling (19) and TMEM16A expression levels decrease during SMC proliferation. However, this is a different process to vascular contraction, which is the focus of the current study. The decline of TMEM16A observed during hypertension in the present study illustrates our hypothesis of the role of TMEM16A in vasoconstriction. Subsequent findings in cultured BASMCs demonstrated that Ang II-induced phosphorylation of MYPT1 and MLC were upregulated by TMEM16A, which confirmed our hypothesis that TMEM16A is involved in cerebral vascular tone.

The small GTPase, Rho and ROCK regulate vascular smooth muscle contraction and blood pressure (43). Once Rho is activated by agonists of receptors coupled to cell membrane G proteins, such as Ang II and phenylephrine, it then activates ROCK. Activated ROCK phosphorylates MYPT1, a subunit of MLC phosphatase, which is then inhibited, leading to phosphorylation of MLC stimulating vascular smooth muscle contraction and cell migration (44). Ang II-induced vasoconstriction in basilar arteries was demonstrated to be predominantly mediated by ROCK using the ROCK inhibitor, Y-27632 (14). In a previous study, ROCK inhibitor, Thiazovivin reversed Ang II-induced MYPT1 and MLC phosphorylation (45); therefore, whether the RhoA/ROCK signaling pathway mediated the effect of TMEM16A on Ang II-induced BASMC contraction was investigated in the current study. The results demonstrated that this was the case and, furthermore, it was found that TMEM16A expression regulated Ang II-induced activation of RhoA. These data are the first, to the best of our knowledge, to provide a mechanism by which TMEM16A contributes to Ang II-induced cerebral vascular constriction.

In conclusion, the current study reveals that TMEM16A, the recently identified component of $\mathrm{CaCCs}$, is involved in Ang II-induced cerebral constriction. Decreased TMEM16A activity and expression reduces basilar artery contractility, and this effect of TMEM16A is mediated by affecting RhoA activation. These data also indicate that Ang II activates TMEM16A-mediated CaCCs in BASMCs. Therefore, TMEM16A has been demonstrated as a potent therapeutic target for the control of vascular function, hypertension and stroke. Future studies are required to determine how TMEM16A affects the RhoA/ROCK signaling pathway, providing a greater insight into the underlying mechanism.

\section{References}

1. Heinze C,SeniukA,SokolovMV,Huebner AK, KlementowiczAE, Szijártó IA, Schleifenbaum J, Vitzthum H, Gollasch M, Ehmke H, et al: Disruption of vascular Ca2+-activated chloride currents lowers blood pressure. J Clin Invest 124: 675-686, 2014

2. Jackson WF: Ion channels and vascular tone. Hypertension 35: $173-178,2000$.

3. Mendelsohn ME: In hypertension, the kidney is not always the heart of the matter. J Clin Invest 115: 840-844, 2005.

4. Yonas H, Smith HA, Durham SR, Pentheny SL and Johnson DW: Increased stroke risk preducted by compromised cerebral blood flow reactivity. J Neurosurg 79: 483-489, 1993.

5. Hill MA, Zou H, Potocnik SJ, Meininger GA and Davis MJ: Invited review: Arteriolar smooth muscle mechanotransduction: $\mathrm{Ca}(2+)$ signaling pathways underlying myogenic reactivity. J Appl Physiol (1985) 91: 973-983, 2001.

6. Earley S and Brayden JE: Transient receptor potential channels and vascular function. Clin Sci (Lond) 119: 19-36, 2010.

7. Rust MB, Faulhaber J, Budack MK, Pfeffer C, Maritzen T, Didié M, Beck FX, Boettger T, Schubert R, Ehmke H, et al: Neurogenic mechanisms contribute to hypertension in mice with disruption of the $\mathrm{K}-\mathrm{Cl}$ cotransporter KCC3. Circ Res 98: 549-556, 2006.

8. Leblanc N, Ledoux J, Saleh S, Sanguinetti A, Angermann J, O'Driscoll K, Britton F, Perrino BA and Greenwood IA: Regulation of calcium-activated chloride channels in smooth muscle cells: A complex picture is emerging. Can J Physiol Pharmacol 83: 541-556, 2005.

9. Wu MM, Lou J, Song BL, Gong YF, Li YC, Yu CJ, Wang QS, Ma TX, Ma K, Hartzell HC, et al: Hypoxia augments the calcium-activated chloride current carried by anoctamin-1 in cardiac vascular endothelial cells of neonatal mice. Br J Pharmacol 171: 3680-3692, 2014.

10. Bulley S, Neeb ZP, Burris SK, Bannister JP, Thomas-Gatewood CM, Jangsangthong $\mathrm{W}$ and Jaggar JH: TMEM16A/ANO1 channels contribute to the myogenic response in cerebral arteries. Circ Res 111: 1027-1036, 2012.

11. Kobori H, Nangaku M, Navar LG and Nishiyama A: The intrarenal renin-angiotensin system: From physiology to the pathobiology of hypertension and kidney disease. Pharmacol Rev 59: 251-287, 2007.

12. Zhang Z, Wang M, Xue SJ, Liu DH and Tang YB: Simvastatin ameliorates angiotensin II-induced endothelial dysfunction through restoration of Rho-BH4-eNOS-NO pathway. Cardiovasc Drugs Ther 26: 31-40, 2012.

13. Hilgers RH, Todd $\mathrm{J} \mathrm{Jr}$ and Webb RC: Increased PDZ-RhoGEF/RhoA/Rho kinase signaling in small mesenteric arteries of angiotensin II-induced hypertensive rats. J Hypertens 25: 1687-1697, 2007. 
14. Faraci FM, Lamping KG, Modrick ML, Ryan MJ, Sigmund CD and Didion SP: Cerebral vascular effects of angiotensin II: New insights from genetic models. J Cereb Blood Flow Metab 26: 449-455, 2006

15. Davis AJ, Shi J, Pritchard HA, Chadha PS, Leblanc N Vasilikostas G, Yao Z, Verkman AS, Albert AP and Greenwood IA: Potent vasorelaxant activity of the TMEM16A inhibitor T16A (inh)-A01. Br J Pharmacol 168: 773-784, 2013.

16. Committee for the Update of the Guide for the Care and Use of Laboratory Animals: Guide for the care and use of laboratory animals. 8th edition. National Academies Press, Washington, DC, USA.

17. Shi XL, Wang GL, Zhang Z, Liu YJ, Chen JH, Zhou JG, Qiu QY and Guan YY: Alteration of volume-regulated chloride movement in rat cerebrovascular smooth muscle cells during hypertension. Hypertension 49: 1371-1377, 2007.

18. Lamping KG, Wess J, Cui Y, Nuno DW and Faraci FM: Muscarinic (M) receptors in coronary circulation: Gene-targeted mice define the role of M2 and M3 receptors in response to acetylcholine. Arterioscler Thromb Vasc Biol 24: 1253-1258, 2004.

19. Wang M, Yang H, Zheng LY, Zhang Z, Tang YB, Wang GL, Du YH, Lv XF, Liu J, Zhou JG and Guan YY: Downregulation of TMEM16A calcium-activated chloride channel contributes to cerebrovascular remodeling during hypertension by promoting basilar smooth muscle cell proliferation. Circulation 125 697-707, 2012.

20. Yang YD, Cho H, Koo JY, Tak MH, Cho Y, Shim WS, Park SP, Lee J, Lee B, Kim BM, et al: TMEM16A confers receptor-activated calcium-dependent chloride conductance. Nature 455: 1210-1215, 2008

21. White CR, Elton TS, Shoemaker RL and Brock TA: Calcium-sensitive chloride channels in vascular smooth muscle cells. Proc Soc Exp Biol Med 208: 255-262, 1995.

22. Guibert C, Marthan R and Savineau JP: Oscillatory Cl-current induced by angiotensin II in rat pulmonary arterial myocytes: $\mathrm{Ca} 2+$ dependence and physiological implication. Cell Calcium 21: 421-429, 1997.

23. Bagi Z, Feher A, Cassuto J, Akula K, Labinskyy N, Kaley G and Koller A: Increased availability of angiotensin AT 1 receptors leads to sustained arterial constriction to angiotensin II in diabetes-role for Rho-kinase activation. Br J Pharmacol 163 1059-1068, 2011

24. Kinlay S, Behrendt D, Wainstein M, Beltrame J, Fang JC, Creager MA, Selwyn AP and Ganz P: Role of endothelin-1 in the active constriction of human atherosclerotic coronary arteries. Circulation 104: 1114-1118, 2001.

25. Liu JQ and Folz RJ: Extracellular superoxide enhances 5 -HT-induced murine pulmonary artery vasoconstriction. Am J Physiol Lung Cell Mol Physiol 287: L111-L118, 2004.

26. Gao YJ and Lee RM: Hydrogen peroxide induces a greater contraction in mesenteric arteries of spontaneously hypertensive rats through thromboxane $\mathrm{A}(2)$ production. Br J Pharmacol 134 1639-1646, 2001.

27. Hall JE: The kidney, hypertension, and obesity. Hypertension 41: 625-633, 2003

28. Hein L: Genetic deletion and overexpression of angiotensin II receptors. J Mol Med (Berl) 76: 756-763, 1998.

29. Crowley SD, Tharaux PL, Audoly LP and Coffman TM: Exploring type I angiotensin (AT1) receptor functions through gene targeting. Acta Physiol Scand 181: 561-570, 2004.
30. Ito K, Hirooka Y, Nakano M, Honda N, Matsukawa R and Sunagawa K: Role of hypothalamic angiotensin type 1 receptors in pressure overload-induced mineralocorticoid receptor activation and salt-induced sympathoexcitation. Hypertens Res 36: 513-519, 2013.

31. Stenman E and Edvinsson L: Cerebral ischemia enhances vascular angiotensin AT1 receptor-mediated contraction in rats. Stroke 35: 970-974, 2004.

32. Toda N, Ayaziki K and Okamura T: Modifications by endogenous prostaglandins of angiotensin II-induced contractions in dog and monkey cerebral and mesenteric arteries. J Pharmacol Exp Ther 252: 374-379, 1990.

33. Billington CK and Penn RB: Signaling and regulation of $\mathrm{G}$ protein-coupled receptors in airway smooth muscle. Respir Res: Mar 14, 2003 (Epub ahead of print).

34. Lu T, Zhang DM, Wang XL, He T, Wang RX, Chai Q, Katusic ZS and Lee HC: Regulation of coronary arterial BK channels by caveolae-mediated angiotensin II signaling in diabetes mellitus. Circ Res 106: 1164-1173, 2010.

35. Ilatovskaya DV, Palygin O, Chubinskiy-Nadezhdin V, Negulyaev YA, Ma R, Birnbaumer L and Staruschenko A: Angiotensin II has acute effects on TRPC6 channels in podocytes of freshly isolated glomeruli. Kidney Int 86: 506-514, 2014

36. Do KH, Kim MS, Kim JH, Rhim BY, Lee WS, Kim CD and Bae SS: Angiotensin II-induced aortic ring constriction is mediated by phosphatidylinositol 3-kinase/L-type calcium channel signaling pathway. Exp Mol Med 41: 569-576, 2009.

37. Caputo A, Caci E, Ferrera L, Pedemonte N, Barsanti C, Sondo E, Pfeffer U, Ravazzolo R, Zegarra-Moran $\mathrm{O}$ and Galietta LJ: TMEM16A, a membrane protein associated with calcium-dependent chloride channel activity. Science 322: 590-594, 2008.

38. Schroeder BC, Cheng T, Jan YN and Jan LY: Expression cloning of TMEM16A as a calcium-activated chloride channel subunit. Cell 134: 1019-1029, 2008.

39. Liu B, Linley JE, Du X, Zhang X, Ooi L, Zhang H and Gamper N: The acute nociceptive signals induced by bradykinin in rat sensory neurons are mediated by inhibition of M-type $\mathrm{K}+$ channels and activation of $\mathrm{Ca} 2+$-activated Cl-channels. J Clin Invest 120: 1240-1252, 2010.

40. Frings S, Reuter D and Kleene SJ: Neuronal Ca2+-activated Cl-channels-homing in on an elusive channel species. Prog Neurobiol 60: 247-289, 2000.

41. Hartzell C, Putzier I and Arreola J: Calcium-activated chloride channels. Annu Rev Physiol 67: 719-758, 2005.

42. Namkung W, Phuan PW and Verkman AS: TMEM16A inhibitors reveal TMEM16A as a minor component of calcium-activated chloride channel conductance in airway and intestinal epithelial cells. J Biol Chem 286: 2365-2374, 2011.

43. Uehata M, Ishizaki T, Satoh H, Ono T, Kawahara T, Morishita T, Tamakawa H, Yamagami K, Inui J, Maekawa $M$ and Narumiya S: Calcium sensitization of smooth muscle mediated by a Rho-associated protein kinase in hypertension. Nature 389 : 990-994, 1997.

44. Sebbagh M, Renvoizé C, Hamelin J, Riché N, Bertoglio J and Bréard J: Caspase-3-mediated cleavage of ROCK I induces MLC phosphorylation and apoptotic membrane blebbing. Nat Cell Biol 3: 346-352, 2001.

45. Cao X,Luo T,LuoX and Tang Z: Resveratrol prevents AngII-induced hypertension via AMPK activation and RhoA/ROCK suppression in mice. Hypertens Res 37: 803-810, 2014. 